\title{
Tecidos decorativos e interiores domésticos oitocentistas na literatura prescritiva inglesa e norte-americana ${ }^{1}$
}

\begin{abstract}
Luz García Neira ${ }^{2}$
RESUMO: Os manuais e jornais de decoração publicados na Inglaterra e Estados Unidos durante o século XIX deram à escolha dos têxteis um papel fundamental na configuração dos ambientes. Têxteis artísticos, artesanais e industriais compartilharam o espaço doméstico, sendo recomendados, em cada situação, conforme seu valor social, diretamente proporcional ao seu valor artístico. Baseado na literatura destinada a auxiliar na decoração doméstica e na bibliografia prévia que explora o assunto, este artigo trata dessa relação e procura demonstrar que com o avanço da industrialização e o crescimento da utilização de tecidos industrializados, valores artísticos foram transmitidos aos tecidos produzidos pela indústria com a intenção de melhorar sua aceitação entre os consumidores.

PALAVRAS-CHAVE: Decoração finissecular. Tecidos decorativos. Manuais de decoração.

ABSTRACT:The handbooks and magazines about decorating that were published in England and North America during the 19th Century meant that the choice of textiles played a key role in shaping the environment. Artistic, craftsman and industrial textiles shared domestic space and in each situation, it was advised that their social value should be directly proportional to their artistic value. This article is based on the literature designed to serve as an aid to house decoration and the bibliography of works that have previously explored this subject. It addresses this relationship and seeks to show that through industrial advances and the growth in the use of industrialized fabrics, artistic values were transmitted to the textiles produced by industry with the aim of ensuring they had a better acceptance among the customers.

KEYWORDS: Fin-de-siècle decorations. Decorative fabrics. Handbooks on decoration.
\end{abstract}

1. Esta pesquisa foi realizada para subsidiar o Projeto de Renovação Museográfica do Museu Casa de Rui Barbosa no período 20102012 e financiada pela Fundação Casa de Rui Barbosa / Ministério da Cultura.

2. Doutora em Arquitetura e Urbanismo pela FAUUSP, docente da Universidade Anhembi-Morumbi, São Paulo. E-mail: <design. textil@uol.com.br>. 
3. Considera-se aqui que as principais capitais europeias e as grandes cidades norte-americanas, assim como o Rio de Janeiro, inserem-se nesse processo de transformação, acelerado tanto pela rápida circulação de artefatos decorativos no Ocidente, quanto por textos normativos que preconizavam seu uso e que constituem a base documental deste artigo. As publicações aqui examinadas encontram-se nos acervos da British Library (Londres) e National Art Library (Victoria and Albert Museum, Londres).

4. Ver Katryn Ferry (2010).

5. Ver Rebeca Houze (2006).

6. Ver Anne Massey (2008).

7. Ver Adrian Forty (2007), para quem os manuais de decoração representam o paradoxo daquela sociedade, que buscava a individualidade mas simultaneamente cerceava e criticava as escolhas individuais que fugissem do que fosse, em cada momento, considerado de bom gosto. Também era uma outra missão dos manuais educar o senso estético da população em geral, de modo a trazer benefícios sociais para além de seus resultados aplicados à decoração doméstica.

8. Conforme apresenta Marize Malta (2011), a Biblioteca de Obras Raras do Museu Dom João VI tem grande quantidade de manuais de decoração do período. Segundo a autora, essas publicações tinham uso pedagógico na Escola de Belas Artes e, por isso, faziam parte da biblioteca. Solange Ferraz de Lima (2008) também elenca a presença de repertórios de ornamentos e similares em bibliotecas e outras instituições em São Paulo (apurando 128 títulos), de modo que ambas as autoras destacam o papel educativo desse tipo de material no Brasil.
A cultura material têxtil nos interiores domésticos oitocentistas

Ao longo do século XIX, os avanços tecnológicos experimentados em diferentes segmentos industriais, trouxeram prosperidade e conforto material às casas urbanas de grande parte das maiores cidades do mundo ocidental ${ }^{3}$ e aos seus proprietários ${ }^{4}$. Tornando-se o consumo um evento social e a posse e a ostentação de produtos industriais e/ou artísticos parte das exigências de socialização distintiva, o ambiente doméstico, segundo Houze, transformou-se numa fonte de prazer e desfrute para a família, o que constitui um excelente exemplo para comprovar a transformação das artes e até mesmo a construção de um novo estilo5.

Em tais circunstâncias, as famílias burguesas, por meio de expressões da cultura visual e material da decoração, desejavam comunicar sua prosperidade econômica. Massey lembra que ao atribuir personalidade à casa a partir das escolhas individuais, contudo, manifestava-se o medo causado pela insegurança que a burguesia tinha com seu próprio gosto ${ }^{6}$, marcando a primeira questão importante a respeito da disseminação dos manuais de decoração ao longo de praticamente todo o século XIX: o conflito entre as preferências pessoais e os mecanismos que ditavam as regras que pretendiam homogeneizar o gosto da população?.

Revistas e livros eram os meios mais comuns de disseminar ou instruir a respeito da decoração da casa, e neles não se alcançou consenso a respeito do que poderia ser considerado a decoração doméstica. Ao longo do século, publicações inglesas e norte-americanas sugeriram a utilização da decoração interior e suas variáveis artísticas para expressar sentidos da sociabilidade, algo que sinaliza que o papel da arte numa sociedade em transformação pela indústria, de algum modo, devia exprimir os valores fundamentais dos indivíduos.

A complexidade dessa relação é identificável nas diferentes perspectivas que a decoração do espaço doméstico assumiu ao longo do tempo, em especial durante o século XIX. Nesse século, a reflexão sobre os interiores domésticos - os elementos e seu arranjo -, foi impulsionada pela consciência das transformações sociais decorrentes da Revolução Industrial expressa tanto nos debates acerca da produção artística e sua seriação, quanto em manuais de decoração e seus postulados de bom gosto. A relação entre a forma dos objetos industriais e a natureza do trabalho na indústria foram questionados do ponto de vista social, religioso, moral e, sem dúvida, estético, tornando-se um debate comum acerca da cultura material na Inglaterra e nos principais centros urbanos da Europa, chegando, inclusive, ao Brasil ${ }^{8}$. Nesse período, destacam-se as três perspectivas a seguir.

Na clássica publicação Hints on Household Taste in Furniture, Upholstery and other details de Charles Eastlake (primeira edição em 1870), por exemplo, considerava-se que "a faculdade de distinguir o bom do mau design nos objetos familiares da vida doméstica é uma faculdade que as pessoas mais educadas - e especialmente as mulheres - devem possuir" ${ }^{\prime \prime}$, atribuindo a competência do gosto à instrução e à moralidade. O Movimento Estético (Aesthetic Movement), por outro lado, mesmo em parte coincidindo com as instruções decorativas do vitorianismo, 
pregava a arte pela arte, evitando o critério decorativo baseado na moralidade burguesa, aceitando, ainda, criação dedicada à conquista da beleza, o que liberava a arte para a criação livre e não só para a reprodução da natureza. Nessa mesma direção, Oscar Wilde (1854-1900) sugeria que a individualidade expressiva poderia ser nociva à noção de beleza artística; apesar de reconhecer que a casa deveria expressar o sentimento daqueles que nela moravam, existiam certos princípios de arte que sempre deveriam ser observados em sua decoração ${ }^{10}$. Uma proposta mais prática - e que deixou seu legado para o século XX -, prezava a decoração racionalizada do ponto de vista plástico. Defendendo que a arte-decoração submetiase à arquitetura, sugeria que os mesmos princípios estéticos fossem seguidos na utilização das cores, materiais, proporções etc., com a finalidade de constituir um sistema decorativo. Desse ponto de vista, embora tais princípios pudessem ser aprendidos por todos, sua aplicação, obviamente, dependeria do decorador ${ }^{11}$.

Beverly Gordon explica que a tradição dos livros de decoração que buscavam a construção do lar ideal associado à moralidade surgiu em decorrência da necessidade de ver materializado o julgamento da mulher no papel de boa esposa e mãe, o que é explicado pelo entendimento que "a mulher era vista como a corporificação da casa, e a casa era vista como a sua extensão, tanto de espírito, quanto corpórea"12. Mas, se as publicações do início do século XIX detinham-se sobretudo em aspectos relacionados à conduta familiar e não exatamente à decoração da casa $^{13}$, a partir das décadas de 1820 e 1830 começaram a ser ofertados livros "totalmente dedicados aos elementos físicos da casa e detalhando como os móveis e decoração poderiam ser empregados em cada cômodo"14 acompanhando, como visto, a própria reflexão teórica a respeito do papel das artes na decoração interior. Não que a mudança na difusão das normas decorativas, tivessem perdido seu caráter moral, mas, adquiriam outra nuance - a finalidade material e igualmente nobre do sentido artístico -, visto que as virtudes que espelhariam ainda davam continuidade às ideias precedentes.

A passagem de uma casa cuja decoração era marcada pelo excesso que buscava o conforto e a ostentação em si mesmos manifestou-se principalmente nas últimas décadas do século XIX, obedecendo aos princípios vitorianos e, portanto, ao exagero, para a construção de um "interior artístico" que contava com a singularidade de seus elementos para simbolizar riqueza, bom gosto e status ${ }^{15}$. Para Martha McClaugherty, o movimento artístico denominado Household Art tinha a intenção "de estabelecer um padrão artístico para a casa para que ela estivesse em harmonia com a recente industrialização da sociedade"16, sendo o consumidor da classe média encorajado a reconhecer o valor do design, promovendo uma interpretação diferente - e valorizável - dos objetos industrializados, ou ao menos dos têxteis. $\bigcirc$ Household Art teria seu fundamento em virtude da proliferação e da grande oferta de itens que rompiam com a tradição artesanal ou artística da produção de objetos cujas virtudes já eram reconhecidas, sendo necessário encontrar o sentido moral do uso dos objetos industrializados, sobretudo em conexão com a vida privada, e dar um novo lugar aos trabalhos femininos, generalizados com o termo trabalho de agulhas.
9. Cf. Charles Eastlake (1869, p. 7).

10. Ver Kevin O'Brien (1974).

11. Ver Candance Wheeler (1903).

12. Cf. Beverly Gordon (1996, p. 282).

13. Ver Margaret Ponsonby (2003).

14. Cf. Margaret Ponsonby (2003, p. 203).

15. Ver Anne Massey (2008).

16. Cf. Marta McClaugherty (1983, p. 1-3). 
17. Cf. Rebeca Houze (2006).

18. Embora as principais transformações da indústria têxtil tenham se dado no século XVIII, a inovação de matérias-primas e aumento de produtividade, deram ao setor um impulso adicional. Assim, o universo dos têxteis no século XIX é muito mais variado e expressivo que no século anterior.

19. As publicações aqui estudadas são inglesas e norte-americanas, mas elas também chegaram ao Brasil na forma de revistas, como $A$ Estação, e livros, como O lar doméstico, publicado por Vera Cleser que contou com várias edições.

20. Ver Margaret Ponsonby (2007).

21. A expressão não pictóri$c a$ que aparece em diversas edições do jornal Decorator and Furnisher, provavelmente sinaliza o desenvolvimento de tecidos industrializados decorados que prescindiam de referências artísticas consagradas, sobretudo a pintura.
Não se pode afirmar com clareza em que medida a população obedecia e seguia os valores disseminados por diversas correntes teóricas da arte e do design presentes nessas publicações, pois, na medida em que a industrialização avançou, tudo o que era novidade era amplamente divulgado e tornado automaticamente a melhor opção decorativa; essa constatação fez com que o senso estético das burguesias urbanas fossem bastante criticados e os critérios para o "bom design" fossem tornados cada vez mais exigentes, justificando a ação das correntes teóricas apresentadas.

As diferentes perspectivas mencionadas foram ditadas por intelectuais, críticos e, sobretudo, arquitetos, que meditavam, via de regra, não só sobre os resultados estéticos alcançados, mas também sobre os modos de produção e os materiais empregados para alcançá-los. Por essa razão, tecidos e espécies afins gozaram de um papel especial na crítica do espaço doméstico, em função da "fascinação pelos têxteis". Tal conceito derivava de Gotffried Semper (1803-1879) e de seus seguidores, que entendiam que, além de serem os têxteis espécies fundamentais na própria concepção da arquitetura, naquele momento, esses seriam "um produto de seu próprio tempo; o maior problema das artes industriais e o grande potencial para construir aquele meio"17, ou, simplesmente, a possibilidade de ver materializada a linguagem da forma.

Assim, na medida em que as tecnologias da indústria têxtil avançaram ${ }^{18}$ e que sua seriação progressiva foi tomando o lugar daqueles tecidos que até então tinham produção limitada, criou-se uma excelente oportunidade para que fossem publicados por tastemakers, arquitetos e outros, inúmeros jornais e livros dedicados a ditar os princípios para a decoração ideal abordando os têxteis, desde sua seleção até seu uso e conservação ${ }^{19}$. Tal literatura, embora abrangente no sentido decorativo, parece ter contribuído para a conformação de gostos e práticas mais ou menos generalizados a respeito dos tecidos decorativos, mesmo que em diferentes perspectivas teóricas ${ }^{20}$, sempre tratando de contemplar suas aspirações.

Os têxteis, em função de sua natureza material, exemplificam fielmente os dilemas do período, sobretudo da oposição entre o período pré-industrial e industrial, muitas vezes presentes no discurso didático dos manuais de decoração. Segundo esses textos, as famílias precisavam estar atentas às armadilhas do design industrial, já que a partir de suas referências não pictóricas ${ }^{21}$, o objeto industrial "penetra e infecta o julgamento pelo qual nós estamos acostumados a selecionar e aprovar os objetos cotidianos que estão ao nosso redor". Esse suposto problema não dizia respeito somente à estética dos objetos, mas também aos materiais utilizados nos processos de produção industriais, cuja qualidade seria bem inferior aos produtos "feitos na época de nossas avós"; haveria ainda uma tendência praticamente dominante para enganar os espectadores, ou pelo uso que encobria os materiais (como os tapetes ou tapeçarias sobre o piso ou a parede), ou para camuflar a verdadeira natureza da peça (como a escultura com pintura marmorizada).

Os manuais deveriam suprir, de maneira pontual, a incapacidade de as pessoas em geral - e até mesmo as mulheres educadas -, teriam de distinguir o bom do mau design, o que no caso dos têxteis requeria grande competência, dada a 
similaridade entre as diferentes qualidades de produtos. Essa capacidade, que deveria ter sido desenvolvida desde a infância por meio da aprendizagem da música, das artes, do conhecimento científico, do senso da beleza, teria dado às jovens esposas as competências necessárias para estimar os méritos da arte-manufatura. Deveria-se evitar que as mulheres fossem levadas pelos ditames da moda, que insistiam em apontar equivocadamente que o novo era sempre o melhor. Daí que, ao contrário desse roldão, muitos manuais identificavam, nas práticas pré-industriais e artesanais e na sua estética, o verdadeiro senso artístico que se perdia à medida em que a industrialização avançava, o que para os tecidos significava um grande problema.

Os têxteis, por essa razão, eram objeto de preocupação dos decoradores, uma vez que tal espécie material foi das mais afetadas pela industrialização, ao lado do mobiliário e das porcelanas. Os tecidos e artefatos afins, sendo imprescindíveis na decoração de qualquer ambiente doméstico, foram considerados um problema por estarem sofrendo grande prejuízo no entender de muitos dos tastemakers. Do ponto de vista do material utilizado, a industrialização alterava as matérias-primas originais; quanto ao desenho, as inovações estéticas, sem "fundamentação pictórica", não eram bem vindas; em termos das ameaças da moda, os padrões eram rapidamente renovados, por serem os desenhos, a partir da mecanização, substituídos com maior facilidade e com baixo custo. Além disso, os tecidos estavam presentes nas paredes, no piso, nas mesas e em todos os cômodos da casa, sem exceção, de modo que nenhum outro tipo de artefato ou recurso decorativo oferecia tantas possibilidades de configurar um erro ou um acerto na decoração22, ainda que, por outro lado, nada os superasse na capacidade de atribuir humanização e personalidade aos ambientes ${ }^{23}$, ou, como diria Gottried Semper, de dar vida e calor à casa. Nesse sentido, sua importância decorativa, pode ser comprovada, inclusive, pela grande quantidade de vezes que foram citados pelos tastemakers e críticos em diferentes impressos, sendo merecedores, inclusive, de seção especial (Figura 1) no jornal Decorator and Furnisher, que abordava em seus artigos aspectos históricos, técnicos e de uso dessa espécie material.

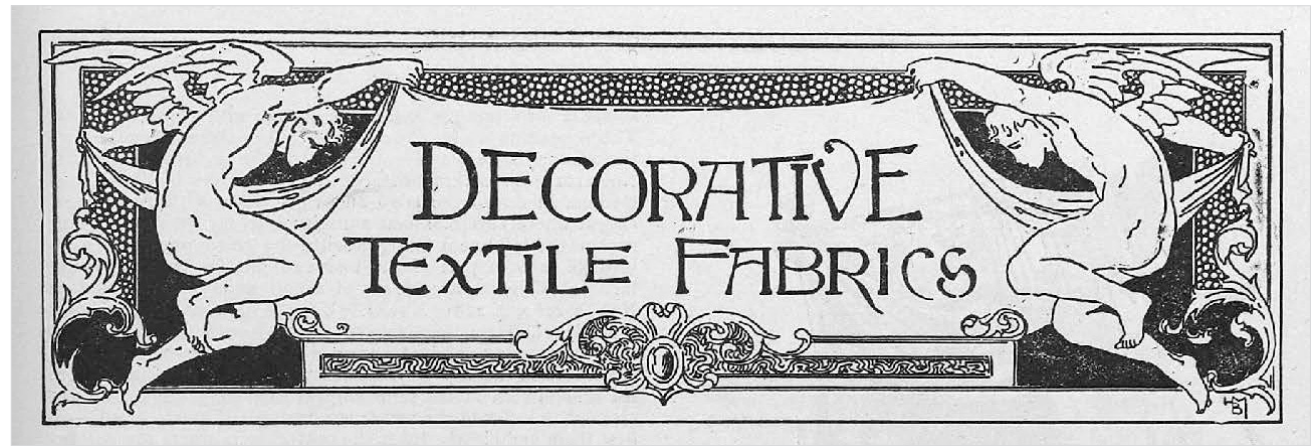

Figura 1 - Cabeçalho utilizado na publicação periódica norte-americana The Decorator and Furnisher, que marca a seção destinada a explicar a utilização de tecidos decorativos que, em matérias com diferentes abordagens, valorizava-os do ponto de vista histórico, apresentava técnicas e inovações etc. Acervo digital da National Art Library (Victoria and Albert Museum, Londres).
22. Ver Charles Warner (1911).

23. Ver Mary Schoeser (2003). 
24. Cf. Margaret Ponsonby (2003, p. 206).

25. Pode-se denominar como tipologia o conjunto de características formais das construções têxteis, o que significa, basicamente, o tipo de estrutura, a matéria-prima utilizada e o padrão ornamental.

26. Cf. Anne Massey (2008, p. 7-8).

27. Ver Beverly Gordon (1996).

28. Apud Margaret Ponsonby (2003).

29. Ver Marta McClaugherty (1983).
Os têxteis e o arranjo decorativo predominante

O uso dos têxteis nas casas teve grande crescimento durante a primeira metade do século XIX, adicionando cor e textura aos interiores, incrementando seu conforto pela eliminação dos assentos rústicos substituídos pelos acolchoados. Têxteis como tapetes e cortinas também tornaram mais leves a arquitetura dos cômodos. Esta tendência foi entendida como a feminização dos interiores ${ }^{24}$.

Margaret Ponsonby

$\bigcirc$ padrão decorativo têxtil mais divulgado, numa análise genérica das casas burguesas, apresenta-se complexo em termos de conteúdo lquantidade e qualidade de tecidos e afins) e composição (a combinação entre eles), correspondendo ao gosto eclético que bem representa o século XIX. Têxteis de diferentes tipologias 25 estiveram presentes em quantidade e qualidade distintas na maioria dos cômodos das casas, sendo a sala de visitas (drawing room), o lugar onde se destacavam:

Este era o ambiente usado para receber visitas, e normalmente tinha cortinas pesadas e rendas volumosas nas janelas, tapetes desenhados, sofás generosamente estofados, mobiliário ornamentado e uma enorme variedade de ornamentos, quadros e superfícies de decoração. A impressão que se desejava exibir era de conforto, riqueza e formalidade ${ }^{26}$.

As diferenças estéticas vividas ao longo do século XIX não alteraram as bases da seleção e uso de tecidos, notando-se a existência de uma ideia predominante acerca da adequação de determinadas tipologias a usos específicos. $\bigcirc$ desejo de demonstrar prosperidade e atualidade (no sentido de estar na moda), era o que dirigia as regras do que devia ou não ser utilizado na casa e que acabou por criar especializações ou distinguiu o uso de determinados artefatos a ocasiões e ambientes, como associar ambientes matinais aos algodões e linhos coloridos e luminosos, e ambientes vespertinos e noturnos a veludos e sedas arranjados de forma complexa com cortinas e aviamentos ${ }^{27}$ (Figura 2).

Embora essa relação tivesse como princípio o desempenho material esperado para cada tecido, o valor social ou psicológico dos têxteis, no entender de Susan Schoelwer ${ }^{28}$, encobriu as funções físicas esperadas de cada material e criou situações de pura cenografia, não exatamente decoração. Era o caso, por exemplo, das cortinas que jamais se fechavam para a proteção da luz solar, e passavam anos servindo apenas de ornamento, ao lado do excesso de cornijas, nós, voltas e outros detalhes constitutivos nada práticos ${ }^{29}$.

Numa época de substituição de espécies artesanais e/ou artísticos pelos industriais, entretanto, a visualidade exibida poderia camuflar o verdadeiro valor dos objetos, de modo que a melhor decoração destacaria para além das qualidades estéticas dos tecidos e afins, as qualidades associadas aos modos de produzi-los. Nessa organização, tinham lugares e valores bem definidos primeiramente as espécies consideradas artísticas, sendo que as artesanais, relacionadas ao trabalho feminino, deveriam resignar-se a espaços, talvez, com 
WYLIE \& LOCHHEAD, LIMITED
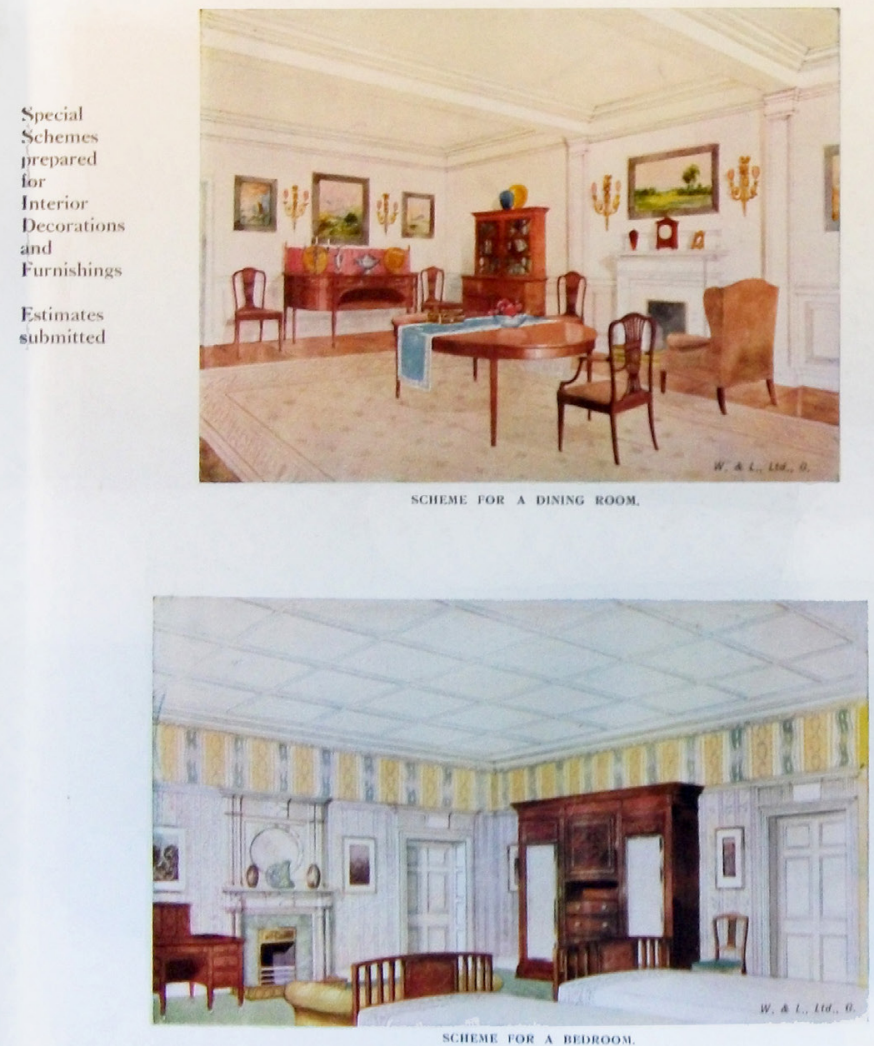

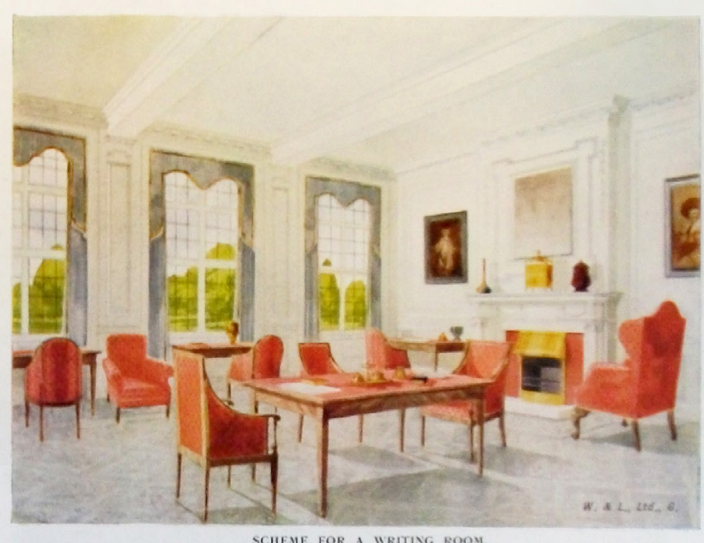

SCIIEME FOR A MRTING ROOM.

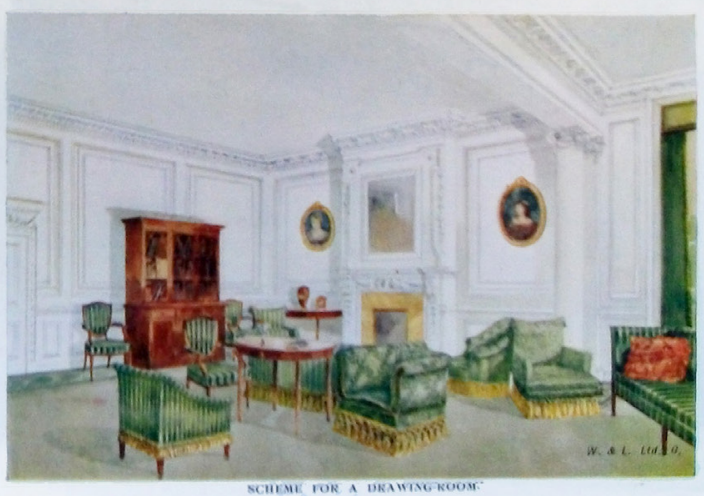

\section{Buchanan Street, Glasgow}

Figura 2 - Sugestão decorativa para quatro distintos cômodos de uma casa publicado no catálogo de vendas da Wylie \& Lochhead Ltd., c. 1890. Além do padrão cromático distintivo a cada cômodo, as marcas de sua ocupação por meio dos têxteis são expressas, por exemplo, na sobriedade e economia de tecidos no escritório - ambiente de trabalho e masculino -, versus a ostentação decorativa com tecidos com pattern e franjas aplicado nos estofados da sala de visitas. Acervo do Museum of Domestic Design and Architecture (MoDA), Middlesex University.

menor importância social. Buscava-se, ainda, um lugar simbólico apropriado para os tecidos produzidos pela indústria para que se pudesse sugerir, adequadamente, - lugar que cada tipologia poderia desfrutar dentro da casa.

Os têxteis decorativos, numa definição bastante generalista, correspondem aos materiais gerados por processos de tecimento ou entrelaçamento de fios ou também por coesão de fibras. Distintas matérias-primas e estruturas de tecimento conferem atributos especiais aos tecidos, ao mesmo tempo em que configuram informações visuais e táteis particulares, permitindo que, pela aparência final, seja identificada sua gênese, que é, na verdade, o que está em julgamento quando se pensam os têxteis como capazes de transportar significados. Dentro do interior doméstico oitocentista, essa variedade era orquestrada, em portiéres ${ }^{30}$,
30. Trata-se de conjunto de sanefa e reposteiros que se colocam nas portas, com a intenção de cobrir os batentes. 
31. Ver Charles Warner (1911).

32. No caso da língua portuguesa, a utilização das terminologias manual e artesanal muitas vezes são usadas de forma indistinta. Neste texto, na maioria das vezes, prefere-se utilizar a expressão manualidade ou manual para dizer que trata-se de um trabalho pertencente ao universo feminino, sem, necessariamente, qualquer conexão que filie quem o realiza à sua linguagem. Prefiro entender que o termo artesanal diz respeito sobretudo às produções manuais ou até mesmo mecanizadas parcialmente, em que o artesão que realiza a atividade tem uma relação cultural com a técnica.

33. Ver Rafael Cardoso (2004).

34. Ver Emma Haywood (1895). cortinas, almofadas, caminhos de mesa, cúpulas de abajures, estofamentos, e uma série de outros incontáveis itens aparentes ${ }^{31}$, além de toda outra gama e variedade que corresponde às espécies usadas nos enxovais, igualmente valiosas e distintivas, mas de uso de serviço, como lençóis, toalhas e similares.

Embora a origem de todos os têxteis seja manual (ou artesanal ${ }^{32}$ ), foi durante a ldade Média que o aperfeiçoamento e especialização de determinadas técnicas fez surgir o que mais tarde nomeou-se de produção artística. Ao valorizar e proteger saberes relativos ao fazer e, ao mesmo tempo, restringi-los a determinados públicos (essencialmente a nobreza e o clero), é que se manteve o uso distintivo de determinadas espécies têxteis até meados do século XVIII, quando a invenção de equipamentos que permitiram a aceleração da produção tornou acessível à burguesia o luxo que antes era restrito à nobreza ${ }^{33}$. Ao mesmo tempo, a produção de algumas espécies que também datavam de tempos medievais mas que eram, em sua maioria, produto do trabalho da mulher - como as rendas e os bordados brancos -, quando não industrializadas, assumiram a forma de manualidades relativas ao universo feminino, cujo valor predominante foi bem mais relativo à moral do que à qualidade da obra em si. Tais trabalhos chegaram a ser citados como um instinto feminino natural e inato, passado de geração a geração ${ }^{34}$, e que, na ausência dessa transmissão direta, poderia ser retomado mediante o ensino preconizado por publicações especializadas em ensina-los (Figura 3).

Ainda que a produção industrial têxtil tenha sido ampliada e diversificada ao longo do século XIX, praticamente não houve inovações em termos de tipologias, nem tampouco extinguiu-se em definitivo qualquer tipo ou modo de produção anterior. Na verdade, pode-se afirmar que a grande mudança deu-se na esfera da circulação dos artefatos, já que ao apropriar-se das técnicas consagradas por meio de tecnologias, a industrialização afetou tanto a produção artística quanto a artesanal. Assim, têxteis e espaços domésticos estabeleceram relações baseadas na sociabilidade potencial dos ambientes, entendendo que estes requisitavam diferentes artefatos para o desempenho de funções práticas e simbólicas simultaneamente.

Assim, grosso modo, a variedade têxtil presente nas casas burguesas podem ser compreendidas por sua categorização, conforme seu modo de produção. Têxteis artísticos seriam o produto de manufaturas, técnicas ou criadores especiais que, dada a consagração de seu feitio ou criador, fossem capazes de conceder distinção social ao seu proprietário, como tapetes e tapeçarias. Têxteis domésticos, artesanais ou, simplesmente, trabalhos de agulha, corresponderiam às espécies produzidas predominantemente pelas mulheres da casa, com a intenção de exibir seus dotes e habilidades, presentes nos enxovais, nos jogos de toalete e na decoração pontual, como em almofadas, de ambientes mais femininos. Por fim, têxteis industriais, cujos valores e reconhecimento ainda não tinham lugar definido, ou seja, tanto poderiam representar o progresso industrial quanto a decadência estética da sociedade, mas estavam em maioria quantitativa dentro das casas, já que estofamentos e cortinas eram, em sua maioria, artefatos que se apresentavam nessa categoria. 
THE

Decorator and Furnisher's Supplement

OF

\section{WORKING DESIGNS FOR MAY, I895.}

No. 1. A Centerpiece in Lace and Embroidery.

No. 2. A Doily in Lace and Embroidery to match.

BY EMMA HAYWOOD.

After a new design by MRS. BARNES BRUCE.

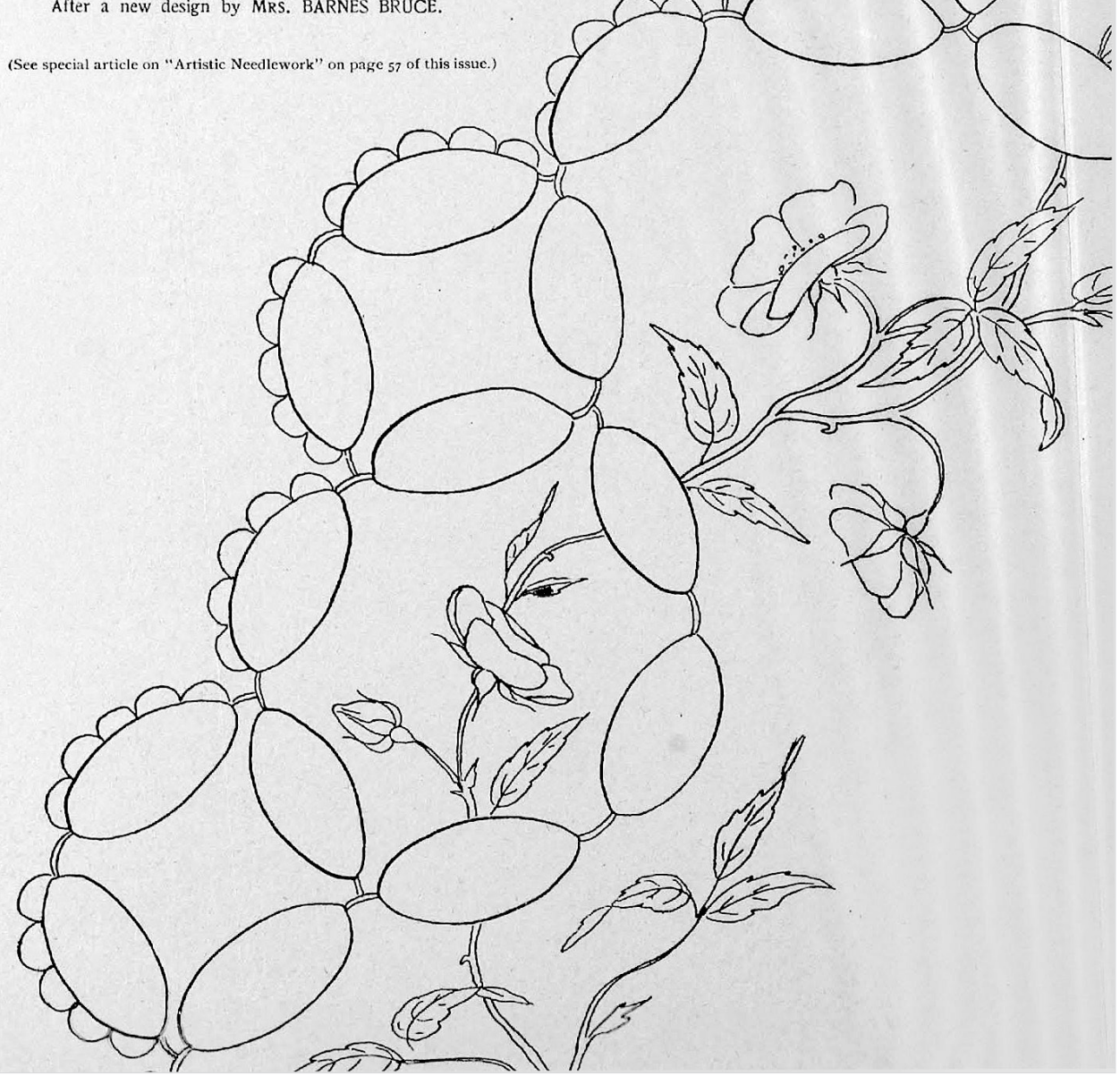

Figura 3 - Suplemento especial do jornal The Decorator and Furnisher, que traz os "riscos" em escala $1: 1$, para que a mulher possa repetir o desenho em seus trabalhos de agulhas. Além do desenho, eram fornecidas, também, a "receita" do bordado, a lista de materiais, entre outras instruções. Acervo digital da National Art Library (Victoria and Albert Museum, Londres). 
35. Ver Margaret Ponsonby (2003).

36. Margaret Ponsonby dedica-se em seu artigo a explicar o conceito de Catherine Grier, que merece aqui ser destacado. Para essa autora, os ambientes sociais deveriam corresponder simultaneamente às necessidades privadas e às públicas, sendo que às primeiras correspondia o conforto e às segundas, que ela chama de culturais, a necessidade de atender obrigações sociais, sendo a principal delas a aparência.

37. Ver Martha Crabill McClaugherty (1983).
O uso mais adequado dessas espécies era sugerida pelos tastemakers para a concepção de cômodos com funções simbólicas bem precisas, que dizem respeito à sociabilidade neles estimada e praticada. Espaços privados diferenciavam-se dos sociais tanto pela mobília quanto pela seleção dos tecidos, autorizando ou proibindo o uso dos ambientes aos habitantes e visitantes da casa. E, ainda, o luxo de um ambiente era medido pela quantidade e tipo de têxteis com os quais tinha sido decorado ${ }^{35}$.

Nos ambientes de cerimônia, onde o conceito de cultura sobrepunha-se ao de conforto ${ }^{36}$, como nas salas de visita ou de jantar, predominavam os tecidos pesados, a ornamentação histórica, os acessórios imponentes, construindo um espaço de distinção; também era a oportunidade de exibir em lugar de destaque, caso houvesse, os melhores tapetes e tapeçarias. Era o momento adequado para utilizar damascos, tafetás e moirés de seda, brocados com fios metálicos e veludos de lã. Nas construções das peças, trimmings, festões, franjas, pingentes e toda espécie de acabamento que desse peso físico e aparência luxuosa aos itens era bem vindo ${ }^{37}$ (Figura 4).

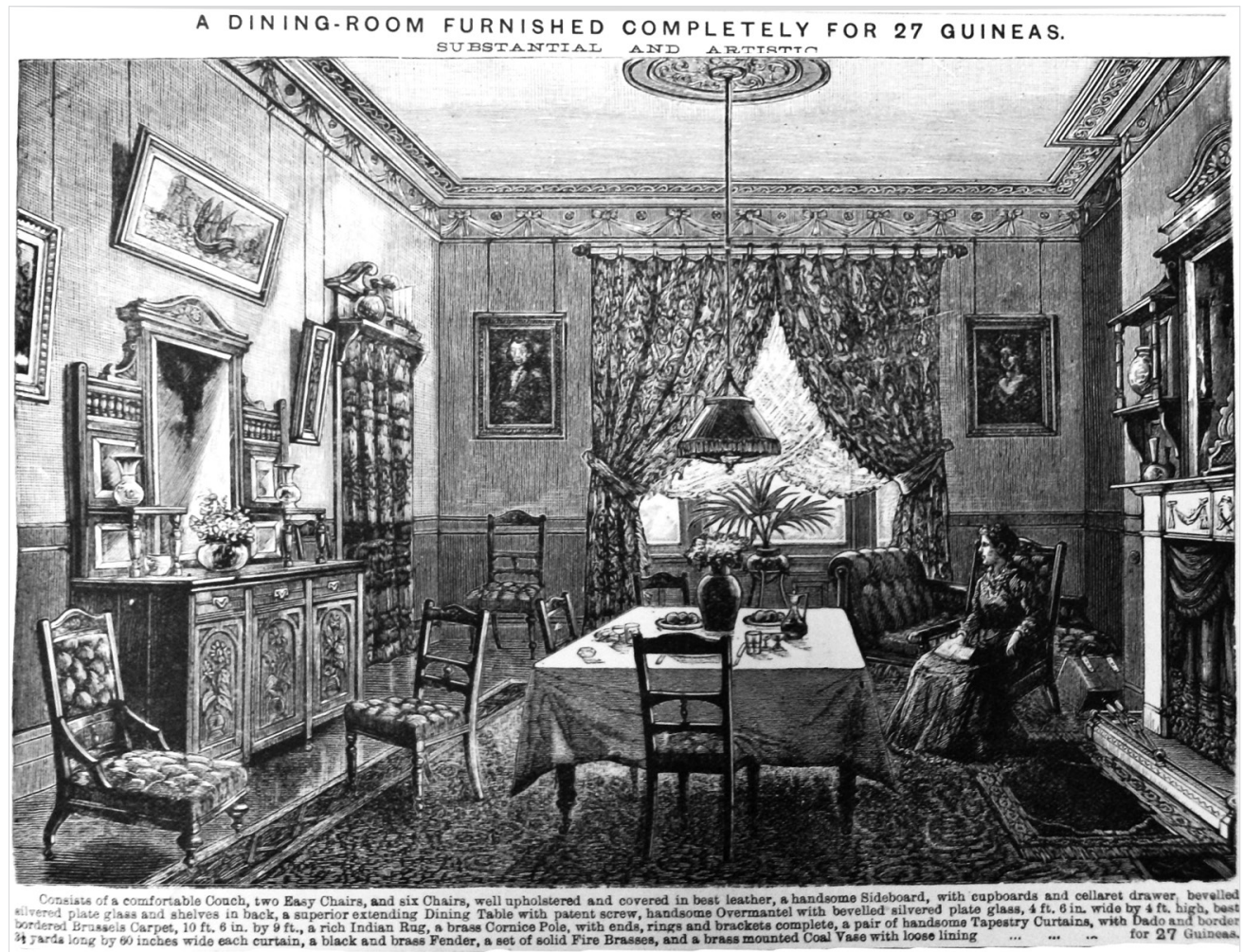

Figura 4 - Sugestão para a decoração de uma sala de jantar, conforme catálogo de vendas de uma loja de departamento inglesa, Oetzmann (c. 1895). O ambiente dá grande destaque aos tecidos, apresentando muitos padrões simultaneamente, indicando (no texto de rodapé) que nas cortinas, nesse caso, devem ser utilizados tecidos de tapeçaria. Acervo do Museum of Domestic Design and Architecture (MoDA), Middlesex University. 
Nos quartos e demais espaços privados, sugeriam-se muitas vezes tecidos mais alegres e leves, que pudessem ser lavados constantemente, correspondendo às perspectivas higienistas da época. Geralmente, preferiam-se os chintz ou cretones com estampas florais ou de folhagens nas sanefas e reposteiros e rendas longas nas cortinas, ainda que brocados de seda, mais leves e sem fios metálicos, também estivessem presentes e fossem muito apreciados.

Os ambientes mais femininos, podiam ainda contar com trabalhos manuais e detalhes ornamentais diversos, como babados e laços, assemelhando-se àquilo que era esperado da aparência do corpo feminino ${ }^{38}$. Diferentes técnicas, modelos, finalidades de trabalhos de agulha, apareciam tanto em toalhinhas sobre todos os móveis de apoio e almofadas decorativas, quanto nas peças de enxoval, tanto para sua identificação, quanto para seu adorno. A casa, assim, por meio dos têxteis, revelava seus códigos de ocupação, inclusive no que tange aos gêneros: enquanto o masculino ligava-se ao sóbrio, à ciência e à modernidade, o feminino conectava-se à emoção e aos sentimentos (Figura 5).

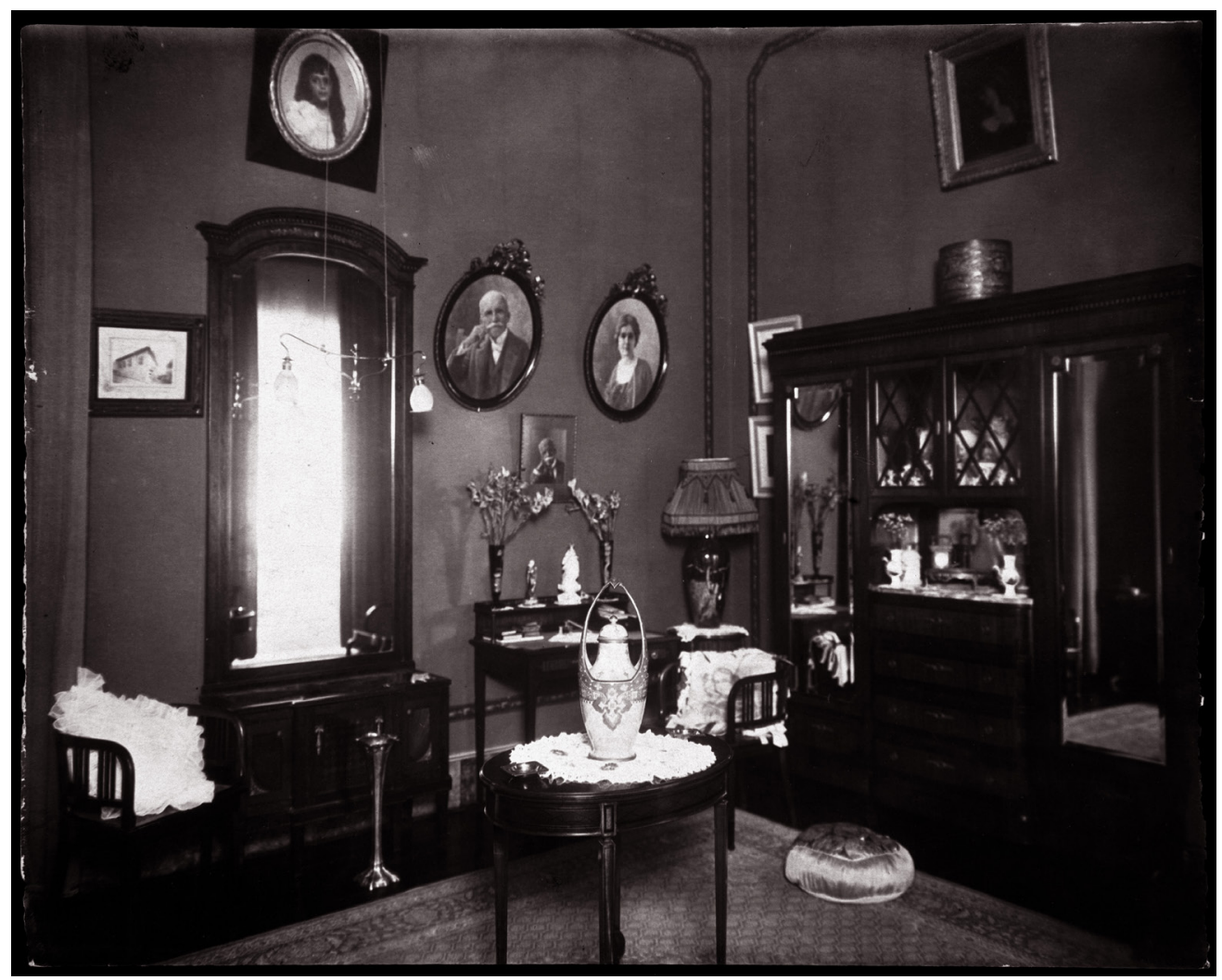

Figura 5 - Exemplo de ambiente feminino exclusivo, como o fitting-room ou quarto de vestir de Dona Maria Augusta (esposa de Rui Barbosa) onde predominam as manualidades em diferentes itens, como almofadas e toalhas sobre os móveis, em conformidade com a literatura prescritiva estrangeira. Acervo do Museu Casa de Rui Barbosa, Rio de Janeiro.
38. Ver Beverly Gordon (1996). 
39. Para a elaboração deste argumento, foram consultados diversos manuais de decoração, artigos em periódicos e livros técnicos sobre a produção têxteis decorativos no período estudado, dentre os quais se destacam os de James Ward (1909), Lucy Abbot Throop (1910), George Hunter (1918), W. Bradshaw (1890), Oliver Bell Junce (1894) e também Carpet Making Review (1884).

40. Cf. Vânia Carneiro de Carvalho (2001).
O padrão decorativo sugerido a partir do uso dos têxteis, correspondendo a um padrão de gosto homogêneo (mas não necessariamente predominante), indica que o sentido do uso de cada tipo de têxtil em sua materialidade, cor, textura e padrão estava previamente determinado pelas regras do bom gosto. Essa relação, derivada da analogia existente entre a materialidade/visualidade e a forma de produção dos têxteis, tinha uma certa estabilidade, já que os valores atribuídos estavam associados à herança histórica carregada por cada espécie, a maior fonte de virtudes que um objeto material poderia exibir. Tais valores, conforme pôde ser verificado, foram emprestadas às espécies industriais cuja forma de produção muitas vezes foi considerada um demérito, ou um lugar de vícios, do qual elas jamais poderiam livrar-se.

Têxteis, vícios e virtudes

O estudo dos manuais de decoração do final do século XIX demonstra, no que diz respeito aos têxteis, que na sua seleção e uso na decoração, a grande preocupação e desafio consistia em integrar diferentes categorias de têxteis dentro dos espaços domésticos ${ }^{39}$. Apesar de o valor artístico da casa dominar o discurso compositivo que constituiria o ambiente ideal, é evidente que os tastemakers não puderam opor-se à industrialização e sugerir a utilização plena de tecidos de manufatura medieval - até mesmo porque atendiam sobretudo à burguesia -, de modo que encontrar um lugar apropriado para a produção têxtil industrial, sem ferir os princípios e valores artísticos que norteavam seu julgamento, era um desafio a ser superado.

A relação entre as espécies materiais têxteis e seu ordenamento no espaço interior doméstico pode ser compreendida a partir do entendimento de que o "modo de apropriação" dos tecidos, quando estes eram colocados em determinados lugares e ambientes, constitui um sistema simbólico em que "a materialidade seria a representação de algo que não está presente" 40 . Assim, ao invés de o julgamento das espécies debruçar-se sobre a visualidade/materialidade dos têxteis, ele atravessava a camada mais superficial da aparência e avaliava seu modo de obtenção em que a genialidade artística ocupava o patamar mais alto de valorização. Uma vez que as espécies legítimas (como tapeçarias, damascos e brocados produzidos manualmente e com exclusividade) não eram tão disponíveis ou acessíveis quanto poderiam ser desejáveis, independentemente da tipologia ou natureza de têxtil, aceitava-se a referência artística na conquista da dignidade moral do material.

A importância do têxtil como suporte de linguagem artística foi tão disseminada na decoração de interiores que suas variedades chegaram a ser equiparadas, pelas publicações do período, às mais notáveis obras de arte. As tapeçarias de diferentes origens, como o Gobelin, Aubusson, Arras entre outras, executadas em seda ou lã, foram destacadas por seu desenho, que exibiam composições pictóricas feitas pelos melhores artistas, além de serem tecidas por tecelões muito habilidosos e especiais, e não por ordinários - como deveriam ser os 
que trabalhavam na indústria; aqueles tecelões dominavam uma técnica exclusiva, que concebia têxteis cuja aparência e leveza não eram possíveis de serem obtidas por qualquer outro tipo ou forma de arte de tecelagem. $\bigcirc$ próprio comprometimento de artistas consagrados em outras artes, como fora o caso de Rafael (1483-1520), que preparou cartoons para a elaboração de grandes tapeçarias murais, servia como prova da nobreza anterior das criações têxteis, que tomavam parte na decoração dos palácios, das igrejas e de outros lugares solenes desde a ldade Média.

Os tapetes orientais, sobretudo as espécies da Pérsia, Turquia e da ĺndia, eram interpretadas como possuidoras de uma "graciosa" harmonia conquistada na mistura de suas cores e, ao mesmo tempo, caracterizadas por possuírem pouco cuidado em seu desenho, o que as tornava ainda mais preciosas. As melhores e mais antigas espécies, segundo Hints on Household Taste, exibiam irregularidades representativas do espírito do bom e nobre design, ao contrário dos tapetes produzidos pelas indústrias europeias que, mesmo pretendendo imitar os originais orientais, eram perfeitamente simétricos, prova irrefutável da falha do design na indústria.

Os trabalhos de agulha - conquanto tenha sido disseminada a ideia de que podiam ser despretensiosos em termos artísticos porque eram produzidos por mulheres e sem aspirações comerciais e apenas zelosas com a família - não fugiam ao crivo do valor artístico. Grande parte dos críticos e tastemakers rebaixara esses têxteis à categoria de fancy work ${ }^{41}$, fazendo com que os trabalhos de agulha perdessem seu lugar dentro da decoração aparente, limitando-se aos espaços privados e tipicamente femininos:

Kits que eram vendidos para as mulheres classe média em meados do século XIX para o bordado de porta-retratos ou buquês florais em cores sintéticas extravagantes para o uso em almofadas ou capas de cadeiras, por exemplo, refletiam, para alguns críticos, o declínio do gosto na classe média ${ }^{42}$.

Enfrentando tais críticas, Lady Alford, por exemplo, explicava no prólogo às suas instruções práticas em Needlwork as Art, publicado em 1886, que seus ensinamentos se dirigiam à maioria das mulheres que não possuíam em sua mente a habilidade artística necessária para a exibição de seu próprio gosto, necessitando de referências que garantissem a origem nobre dos desenhos e padrões; tal argumento justificava, por si só, as inúmeras publicações que reproduziam padrões e davam as instruções necessárias para a produção dos trabalhos domésticos. Já Emma Haywood, em seus inúmeros artigos publicados em The Decorator and Furnisher nas décadas de 1880 e 1890, afirmava que pretendia elevar o conceito dos trabalhos de agulha ao patamar da arte, pois, naquela época, ele estava sendo encarado como um hobby feminino (Figura 6), o que causava seu desprestígio. Assim, trilhando o caminho mais óbvio em busca do reconhecimento - pois os manuais de decoração não tinham tanta certeza de que os trabalhos manuais deveriam ocupar um lugar de destaque na decoração -, houve empenho das mulheres dedicadas às agulhas em investigar a origem, a prática e a nobreza dos
41. Cf. Mary Gay Humphrey (1885).

42. Cf. Rebeca Houze (2006). 
43. Pelo menos desde a segunda metade do século XIX, com organização e controle inglês, formaram-se diferentes centros de produção de tapetes no Oriente, sob encomenda comercial europeia. Nessas ocasiões, havia interferência sobre o desenho original para o atendimento do gosto ocidental.

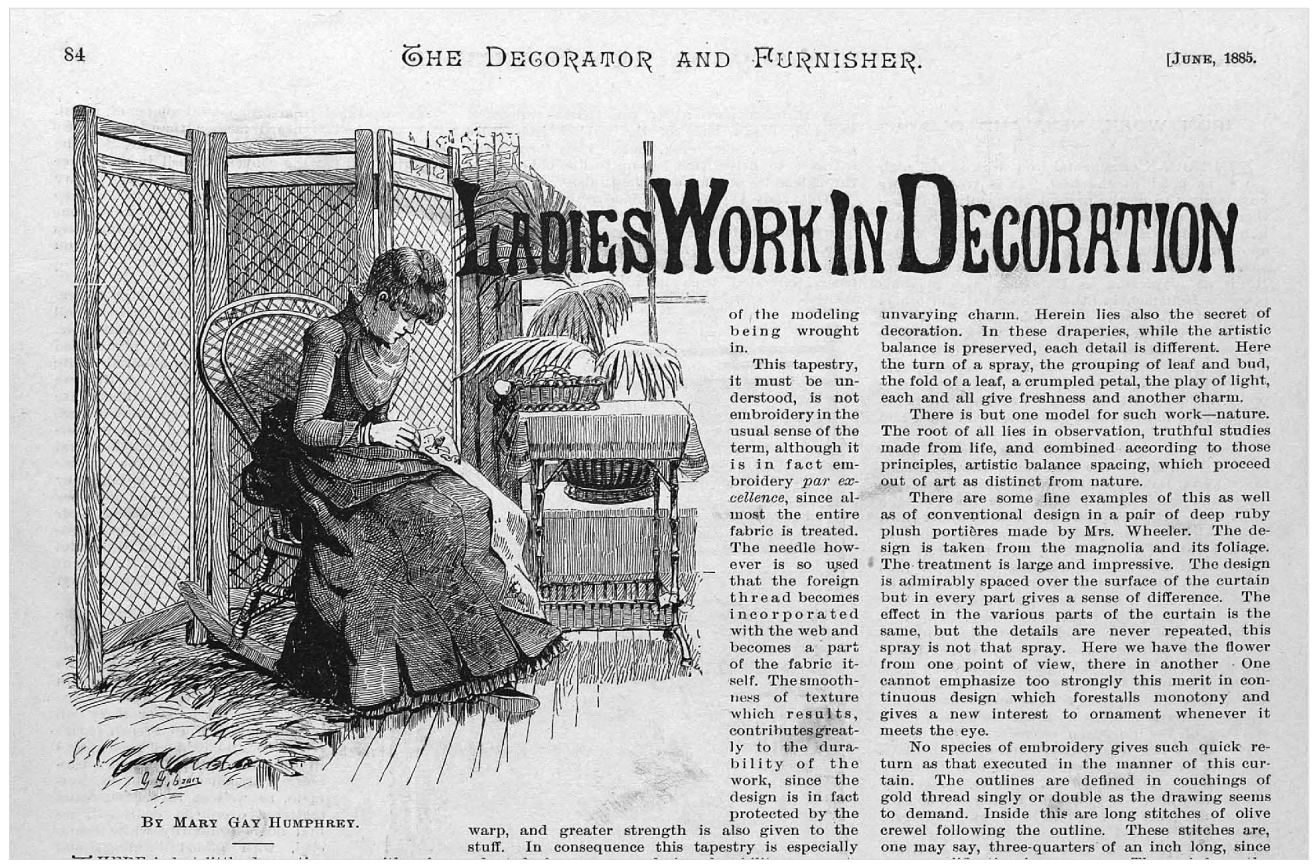

Figura 6 - Cabeçalho da seção dedicada aos trabalhos de agulhas no jornal The Decorator and Furnisher (1885), que evidencia a visão existente sobre a elaboração do trabalho de agulhas, por meio da ilustração da mulher bordando em uma cadeira de balanço. Acervo digital da National Art Library (Victoria and Albert Museum, Londres).

bordados desde a Idade Média, o que justificaria sua presença nos interiores domésticos, sobretudo na obtenção de ambientes de bom gosto. Para os críticos de tais habilidades, entretanto, a ideia da reprodução de técnicas e de motivos ancestrais, como os livros para trabalhos manuais para senhoras sugeriam, comprovava que os trabalhos femininos constituíam uma arte puramente imitativa, sem nada de inventivo e sem conexão com o tempo presente.

Mas a grande crítica, sem dúvida, recaía sobre o acesso a determinadas espécies têxteis promovido pela industrialização ou simplesmente pela mercantilização da arte. No caso da produção sob encomenda de tapetes indianos em Masulipatam, por exemplo, entendia-se que a busca pelo barateamento das espécies originais, para possibilitar seu comércio de forma mais abrangente na Europa ${ }^{43}$, estava promovendo mudanças deploráveis. Além disso, para os críticos, quando, por exemplo, a indústria de tapetes prescindia das referências orientais criava verdadeiras monstruosidades pictóricas, principalmente quando os tapetes deixavam de ser flat, para fazer representações naturalísticas, diretas e tridimensionais da natureza.

Vivia-se uma época em que qualquer tipo de obra de arte estava sendo substituída - ou tornando-se acessível - por cópias industrializadas e os tastemakers, embora não abandonassem o discurso do valor artístico, não poderiam afastar-se da realidade. Inicialmente, insistiu-se em afirmar que, embora os melhores tecidos decorativos típicos da Idade Média agora pudessem ser reproduzidos pelos teares 
mecânicos com o dispositivo jacquard44, e "por mais maravilhosos que fossem", a produção industrial não conseguia manter "a alta classe dos tecidos, como brocados, finos veludos e similares", simplesmente porque os velhos teares eram acionados pelos pés, reconhecia-se que tal modo de produção seria irrecuperável. Desse modo, ainda que, a própria proletarização do trabalho artístico vinha sendo objeto de críticas intensas, o estímulo ao uso da referência artística já consagrada, que poderia ser conquistado pela cópia ou pela inspiração, fazia sentido. Na maioria das vezes foi um bom instrumento para legitimar o valor dos tecidos industriais, a ponto de, finalmente, os vícios da produção industrial darem lugar às virtudes da máquina, na qual residia o grande apelo do progresso e do desenvolvimento das nações mais industrializadas. Na verdade, a máquina até poderia ter tornado os ambientes domésticos atuais "mais artísticos" que os anteriores:

Há tempos atrás - e não faz muitos anos - as draperies, agora vistas na decoração das casas de nosso país, eram uma exceção e não uma regra. Em algumas das mais luxuosas casas, as draperies estavam presentes, mas, na maioria dos exemplos, e com a exceção das janelas em virtude do óbvio propósito de criar a sombra, o cortinamento era desconhecido, e o efeito das portas sem acabamento e a falta de toque artístico no drapejado dos quadros ou de outros móveis prevalecia. Mas isso tudo mudou ${ }^{45}$.

A prática decorativa mudou na opinião daqueles observadores, pois o uso não funcional dos têxteis tornou-se mais comum nas casas. A produção industrial aumentou a quantidade de tecidos disponível no mercado e chegou a ser vista como uma continuidade ou até mesmo como uma melhoria de "uma arte milenar" como a tecelagem. Isso era possível, graças aos "maravilhosos" equipamentos jacquard:

A decoração de paredes com a colocação de tapeçarias é reconhecidamente o mais alto estilo de decoração mural. Esplêndidos tecidos como as tapeçarias feitas a mão de Gobelin e Aubusson, ou outros mais econômicos mas não menos suntuosos produtos dos teares jacquard, que exibem reproduções magníficas de paisagens, cenas históricas, de caça, de personagens históricos etc. [...] proporcionam a impressão de magnificência e repouso assim como qualquer outro tecido decorativo ${ }^{46}$.

Tornando-se mais rápido o trabalho de produção, outro fenômeno interessante relativo aos tecidos foi a possibilidade de seu uso generalizar-se como uma moda, ainda que, como dito anteriormente, seus excessos devessem ser combatidos. Só a grande oferta de determinadas espécies poderia provocar a sensação de que haveria, afinal, uma estética ideal e predominante, que poderia e deveria ser seguida:

A cortina mais popular no mercado é sem dúvida a rede suiça. $\bigcirc$ uso corriqueiro de máquinas para a produção de cortinas já deixou sua marca na manufatura desses itens; a musselina aplicada que servia [anteriormente] como estrutura para o trabalho manual [...], é agora, na maioria dos casos, efetuada pelo mais alto mecanismo [...]. Nessas condições, o custo da produção foi consideravelmente reduzido, mas o artigo ainda mantém suas qualidades originais de durabilidade e aparência ${ }^{47}$.
44. A designação jacquard, comum a muitos tecidos, inclusive atualmente, na maioria das vezes designa aqueles que são desenhados durante o próprio tecimento, com o uso de fios coloridos ou não, resultando em imagens, relevos e outros. Jacquard é o nome dado a um dispositivo que pode ser aplicado a inúmeros tipos de teares, o que possibilita esse tipo de produção descrita. Por declinação, acostumamo-nos a nomear os tecidos como jacquard com se fosse uma tipologia, que, no entanto, no caso dos tecidos de decoração, é o brocado, o damasco, o gobelin entre outros, que, na maioria das vezes dos processos industriais, são produzidos por teares aos quais são acoplados os dispositivos jacquard. O nome jacquard deriva do sobrenome do inventor de tal dispositivo.

45. Cf. S. Putnam (1894, p. 97).

46. Cf. Brabant Tapestry (1894, p. 17).

47. Cf. Ada Cone (1893, p. 99). 
48. Cf. E. Lander (1883, p. 159).

49. No ano de 1926 a fotogravura passou a ser utilizada na indústria têxtil, como técnica de elaboração de matrizes para a estamparia.
Passou-se a entender, ou a pelo menos divulgar-se, que o desenvolvimento mecânico não tinha alterado os fundamentos artísticos da arte da tecelagem, o que poderia ser comprovado pela existência de uma enorme quantidade de padrões que se fundamentavam no passado. Brocados com desenhos chineses, bizantinos, persas ou europeus tradicionais, constituíam uma rica inspiração, que impedia que os originais fossem considerados mais belos que os produzidos naquele momento:

Com o aperfeiçoamento de sua fabricação, o rico veludo de seda que cujo preço é $\$ 75$ por jarda é um dos mais belos materiais usados no estofamento. A partir de sua produção nos teares Jacquard e seu bordado manual, representa, em cores velhas, um tecido antigo. [...] Outro material com o mesmo nível de luxo é um brocado de seda feito o estilo de decoração Luis XVI, que também é tecido e bordado por uma máquina destinada a esse uso especial ${ }^{48}$.

Os tecidos que tinham notabilizado a ldade Média e o Renascimento e que deles tinha-se conhecimento graças aos fragmentos e às pinturas, agora, "graças as condições modernas de produção [...] são parte da vida cotidiana", sendo tão dignos em termos de beleza, design e habilidade de produção quanto os antigos. Também as paredes dos interiores oitocentistas podiam desfrutar da riqueza da arte mural da tapeçaria graças ao jacquard, pois qualquer tipo de tapeçaria tornara-se acessível, além de não haver mais nenhum tipo de proibição de desenho e de uso imposto pela nobreza. A invenção de Joseph-Marie Jacquard (1752-1834) foi então, finalmente, considerada um marco no início de uma nova era.

Estabelecidos novos modos de produção e sobretudo de ornamentação de tecidos - primeiramente durante a tecelagem (por meio do dispositivo jacquard) e, nas primeiras décadas do século XX, também no processo de estamparia ${ }^{49}$, pois até mesmo a qualidade dos chintz indianos, em cores e desenhos por tantos anos inimitável, passou a ser multiplicada pela máquina - pode-se afirmar que a burguesia acabou por aceitar a produção industrial têxtil, tornando-se essa por fim, em algumas circunstâncias, um produto de luxo para uso decorativo. Por outro lado, com o avançar das ideias modernistas nas primeiras décadas do século XX, a crítica ao ornamento acabou por abalar os pressupostos criativos que dominavam a produção têxtil industrializada o que significou um rompimento definitivo com o sistema de valores do século XIX baseados na citação de modelos antigos e na suntuosidade decorativa.

Considerações finais

Como visto, a partir da problematização dos interiores domésticos do século XIX preconizados pelos manuais e textos normativos para decoração, foi possível perceber o lugar de destaque que os têxteis tiveram para a expressão da imagem que as sociedades burguesas desejavam. $\bigcirc$ uso correto dos têxteis produzidos pela indústria em larga escala era definido tanto pela função dos cômodos quanto pela ocasião em que seriam utilizados. Assim, a produção seriada, ao invés de homogeneizar a visualidade do uso decorativo nos têxteis, a 
especializou ainda mais, diferenciando as categorias de uso e marcando suas oposições, como feminino/masculino, privado/público, dia/noite, trabalho/lazer, etc.

Não é possível saber, contudo, em que medida as ordens compositivas ditadas pelos manuais de decoração oitocentistas foram seguidas, mas ainda assim tais impressos são úteis para apontar as referências principais acerca do que podia ser então considerado o ideal de comportamento e de gosto. Percebe-se, também, a mudança gradual de mentalidade com relação à produção artística industrializada, cujos artefatos, inclusive os têxteis, passam de um discurso negativo e condenatório da produção mecanizada, ao entendimento da disponibilidade material como um valor meritório. Passou-se, portanto, de mera oferta ao reconhecimento de novas linguagens, características da era industrial.

\section{REFERÊNCIAS}

BRABANT Tapestry. The Decorator and Furnisher, Nova York, v. 25, n. 1, p. 17, out. 1894.

BRADSHAW, W. R. Occidental Draperies. The Decorator and Furnisher, Nova York, v. 16, n. 4, p. 119-122, jul. 1890 .

BUNCE, Oliver Bell. The Season's Draperies. The Decorator and Furnisher, Nova York, v. 25, n. 2, p. 57-58, nov. 1894 .

CARDOSO, Rafael. Uma introdução à bistória do design, 2 ed. São Paulo: Edgard Blücher, 2004.

CARPET Making Reviewed. The Decorator and Furnisher, Nova York, v. 4, n. 1, p. 15, abr. 1884.

CARVAlHO, Vânia Carneiro de. Gênero e cultura material: uma introdução bibliográfica. Anais do Museu Paulista: História e Cultura Material, São Paulo, v. 8-9, p. 293-324, 2001.

CONE, Ada. Parisian Portieres and Window Draperies. The Decorator and Furnisher, Nova York, v. 22, n. 3, p. 97-99, jun. 1893.

FERRY, Kathryn. The Victorian Home. Oxford: Shire Publications, 2010.

FORTY, Adrian. Objetos de desejo. Design e sociedade desde 1750. São Paulo: Cosac \& Naif, 2007.

GORDON, Beverly. Woman's Domestic Body: The Conceptual Conflation of Women and Interiors in the Industrial Age. Winterthur Portfolio, Chicago, v. 31, n. 4 (Gendered Spaces and Aesthetics), p. 281-301, inv. 1996.

HAYWOOD, Emma. Artistic Needlework. The Decorator and Furnisher, Nova York, v. 26, n. 2, p. 57-59, mai. 1895. 
HOUZE, Rebecca. The Textile as Structural Framework: Gottfried Semper's Bekleidungsprinzip and the Case of Vienna 1900. Textile - The Journal of Cloth and Culture, Letchworth, v. 4, n. 3, p. 292-311, outono 2006.

HUMPHREY, Mary Gay. Ladies Work in Decoration. The Decorator and Furnisher, Nova York, v. 6, n. 3, p. 84-86, jun. 1885 .

HUNTER, George. Decorative textiles. An illustrated book on coverings for furniture, walls and floors, including damasks, brocades and velvets, tapestries, laces, embroideries [...]. Filadélfia e Londres: J. B. Lippincott, 1918.

LANDER, E. T. Resources in Upholstery. The Decorator and Furnisher, Nova York, v. 1, n. 5, p. 159-160, fev. 1883.

LIMA, Solange Ferraz de. O trânsito dos ornatos: modelos ornamentais da Europa para o Brasil, seus usos (e abusos?). Anais do Museu Paulista: História e Cultura Material, São Paulo, v. 16, n. 1, p. 151-199, jan.-jun. 2008.

MALTA, Marize. Aprender a ver: modelos para o decorativo nas Obras Raras do Museu Dom João VI. Anais do XXXI Colóquio do Comitê Brasileiro de História da Arte. Campinas: UNICAMP, 2011.

MASSEY, Anne. Interior Design since 1900. Londres: Thames and Hudson, 2008.

McCLAUGHERTY, Martha. Creating the artistic home, 1868-1893. Winterthur Portfolio, Chicago, v. 18, n. 1, p. 1-26, primav. 1983.

O'BRIEN, Kevin. "The House Beautiful”: A Reconstruction of Oscar Wilde's American. Victorian Studies, Bloomington, v. 17, n. 4, p. 395-418, jun., 1974.

PONSONBY, Margaret. Ideals, Reality and Meaning. Homemaking in England in the First Half of the Nineteenth Century. Journal of Design History, Oxford, v. 16, n. 3, p. 201-214, 2003.

Stories from Home. English domestic interiors, 1750-1850. Aldershot: Ashgate, 2007.

PUTNAM, S. A. Brock. Simpler Varieties of Draperies. The Decorator and Furnisher, Nova York, v. 25, n. 3, p. 97-100, dez. 1894.

SCHOESER, Mary. World Textiles. A Concise History. Londres: Thames and Hudson, 2003.

THROOP, Lucy Abbot. Furnishing the Home of the Good Taste. Nova York: McBride, 1910.

WARD, James. Historic Ornament. Treatise on Decorative Art and Architectural Ornament. Londres: Chapman and Hall, 1909.

WARNER, Charles. Home decoration. Chicago: McGowen-Maier, 1911.

WHEELER, Candance. Principles of Home Decoration. With practical examples. Nova York: Doubleday, Page, 1903.

Artigo apresentado em 02/08/2012. Aprovado em 27/04/2014. 